\begin{tabular}{|c|c|c|}
\hline$\overbrace{\text { BENTHAM OPEN }}$ & $\begin{array}{c}\text { The Open Chemical Engineering } \\
\text { Journal }\end{array}$ & 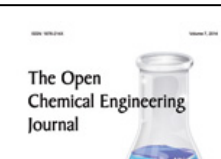 \\
\hline CrossMark & $\begin{array}{l}\text { Content list available at: www.benthamopen.com/TOCENGJ/ } \\
\text { DOI: } 10.2174 / 1874123101610010004\end{array}$ & Exalines: \\
\hline
\end{tabular}

\title{
Useful Bioactive Substances from Wastes: Recovery of Trans- Resveratrol from Grapevine Stems
}

\author{
George Angelov ${ }^{*}$, Lubomir Boyadzhiev and Silviya Georgieva \\ Institute of Chemical Engineering, Bulgarian Academy of Sciences, Sofia, 1113, Bulgaria
}

\begin{abstract}
The methods for producing natural resveratrol are of big interest because of the many health benefits of this substance and its increasing use in functional foods, food supplements and para-pharmaceutical preparations. Generally, resveratrol is extracted from different natural sources, most of them usually produced for consumption purposes (grapes, nuts). This paper presents a method for recovery of resveratrol from a widely available raw material - grapevine stems, a by-product of vine pruning. An efficient extraction-fractionation scheme is developed, based on shifting the phase equilibrium, by which more concentrated extracts of resveratrol are obtained. After a simple extraction, the initial extract is further separated into two fractions, containing either water or ethanol-soluble compounds. Using this approach, the resveratrol's low water solubility helps isolate it from other water-soluble substances. The resulting product is almost ten times more concentrated in trans-resveratrol than the initial total extract. Additionally, a fraction containing water-soluble polyphenols is obtained, which could be used for water-based pharmaceutical and cosmetic preparations.
\end{abstract}

Keywords: Extraction, grapevine stems, polyphenols, resveratrol.

\section{INTRODUCTION}

Resveratrol (3,5,4'-trihydroxystilbene) is a natural phenol compound which belongs to the stilbene family. It was first isolated from a poisonous plant, Veratrum album [1]. Due to its many health benefits, this substance is the subject of intensive research. Resveratrol exists as two structural isomers-cis and trans. Resveratrol's trans-isomer is stable, has better biological activity, and is naturally produced by some plants as a self-defense agent in response to fungal infection, injury, or exposure to ultraviolet light $[2,3]$.

Resveratrol is found in more significant quantity in the roots of Japanese knotweed (Itadori plant, Polygonum cuspidatum), in grapes and in many other fruits and vegetables commonly used for human consumption, e.g. peanuts, blueberries, cranberries, mulberries etc. [4 - 6].

Numerous studies on resveratrol have demonstrated positive health effects such as reduced coronary heart disease and atherosclerosis [7, 8], reduced effects of some neurological diseases (Alzheimer, Parkinson) [9] and carcinogenesis [10]. Resveratrol helps counteract the detrimental effects of a high-fat diet [11,12] and shows ability to increase stress resistance and lifespans [13].

Due to its significance in both plant protection and human health, there is growing interest in the extraction of resveratrol from different natural sources, most of them usually produced for consumption purposes (grapes, nuts). While there is already evidence of high resveratrol concentration in grape berries and red wine, there is recent information for its presence in the grapevine itself. Resveratrol concentration varies by plant part and is highest in the stems and minimal in the leaves [14]. This is why grapevine stems, which are by-products of vine pruning usually destroyed by burning, can be regarded as a widely available potential source of natural resveratrol.

\footnotetext{
"Address correspondence to this author at the Institute of Chemical Engineering, Bulgarian Academy of Sciences, Acad. Bonchev St., Block 103, 1113 Sofia, Bulgaria; Tel: +35929793286; E-mail: gang@bas.bg
} 
Almost insoluble in water, resveratrol has been extracted by numerous organic solvents or their mixtures with water [15]. Previous studies on extraction of resveratrol from grapevine stems have revealed the importance of the dielectric constant of organic or organic-water solvents on the extraction yield [16]. The most commonly used solvent is an ethanol-water mixture [16 - 20]. A multi-step extract-enrichment process using a rather specific and low-capacity laboratory technique has been previously proposed for the separation of resveratrol from the crude ethanolic extract: preparative column chromatography on polyamide carrier [21]. In general, the reported studies aim to obtain better yields and more concentrated extracts of resveratrol. The purpose of the present work is to treat the extraction of grapevine stems in a more complex manner, combining better yield of total extract and separation of organic-soluble polyphenols, including resveratrol, from water-soluble polyphenols. On one hand, such separation is a way to obtain more concentrated resveratrol fraction, and on the other hand, it allows the recovery and further use of the water-soluble polyphenols present in the total extract.

\section{EXPERIMENTAL}

\subsection{Plant Material}

The solid matter to be extracted consists of dry vine stems of Cabernet Sauvignon cultivar from Plovdiv region of Bulgaria, year 2012. They are disintegrated into 1-2 $\mathrm{mm}$ particles.

\subsection{Chemicals and Analyses}

Trans-resveratrol, acetonitrile, Folin-Ciocalteu reagent (2N solution) and Gallic acid (GA) were provided by SigmaAldrich (Germany). Ethanol 96\% and dehydrated $\mathrm{Na}_{2} \mathrm{CO}_{3}$ were purchased from Valerus (Bulgaria). The solvent was a mixture of $77 \%$ ethanol and $23 \%$ water.

Analyses were made for trans-resveratrol (TR) and total polyphenolic content (TPC) of the products obtained.

\subsection{Trans-Resveratrol}

HPLC reverse-phase methods are typically more convenient than other forms of liquid chromatography [22]. Analyses were performed using a Knauer HPLC system comprised of a sample injector, Knauer Smartline Menager 5000, Knauer Smartline Pump 1000, and variable wavelength detector. Trans-resveratrol peak areas were determined at $306 \mathrm{~nm}$. Analyses were performed by using C-18 Supelco column (250 mm, $4.6 \mathrm{~mm})$. The mobile-phase flux was 0.6

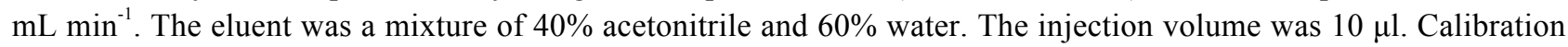
was done using trans-Resveratrol solutions $0.1-0.5 \mathrm{~g} \mathrm{~L}^{-1}$. Trans-resveratrol standard was stored at low temperature $\left(4^{\circ} \mathrm{C}\right)$ in a flask wrapped with aluminum foil to minimize light-induced isomerization.

\subsection{Total Polyphenolic Content $\left(\mathrm{TPC}_{\mathrm{GA}}\right)$}

TPC was determined by the standard method using Folin-Ciocalteu reagent [23]. The treated extract samples obtain a color proportional to their TPC. Their light absorbance was analyzed with double-beam UV-VIS-spectrophotometer (UNICAM ${ }^{\circledR}-$ Helios $\beta$ ) at $765 \mathrm{~nm}$ and the TPC was evaluated comparatively to a calibration line obtained with Gallic Acid as a standard $\left(\mathrm{TPC}_{\mathrm{GA}}\right)$.

\subsection{Yield of Dry Extract}

It was obtained by evaporation of the liquid extracts at mild temperature $\left(80^{\circ} \mathrm{C}\right)$ and weighting of the dried solid residue.

\subsection{Experimental Procedure}

The solvent used is $77 \mathrm{v} \% / 23 \mathrm{v} \%$ ethanol/water mixture, which is in the $70-80 \%$ ethanol content range found to have high extraction affinity to resveratrol [16].

As reported, the extraction yield is improved when raising the temperature [17], undoubtedly due to increased solubility at higher temperatures. Consequently, the extraction is conducted at solvent's boiling point under reflux. Additional agitation is not applied because the convective agitation at boiling is rather intensive.

Our preliminary study has shown that solvent-to-solid ratio (hydromodule) of at least 5:1 is necessary for good wetting of raw material and for providing efficient interphase contact. At this or higher hydromodule, solubility 
constraints due to insufficient quantity of solvent are avoided. Also, our kinetic studies have shown that processing time of about 1 hour is enough for completing the extraction (see Fig. 1). Longer phase contact does not result in higher yield of extracted matter.

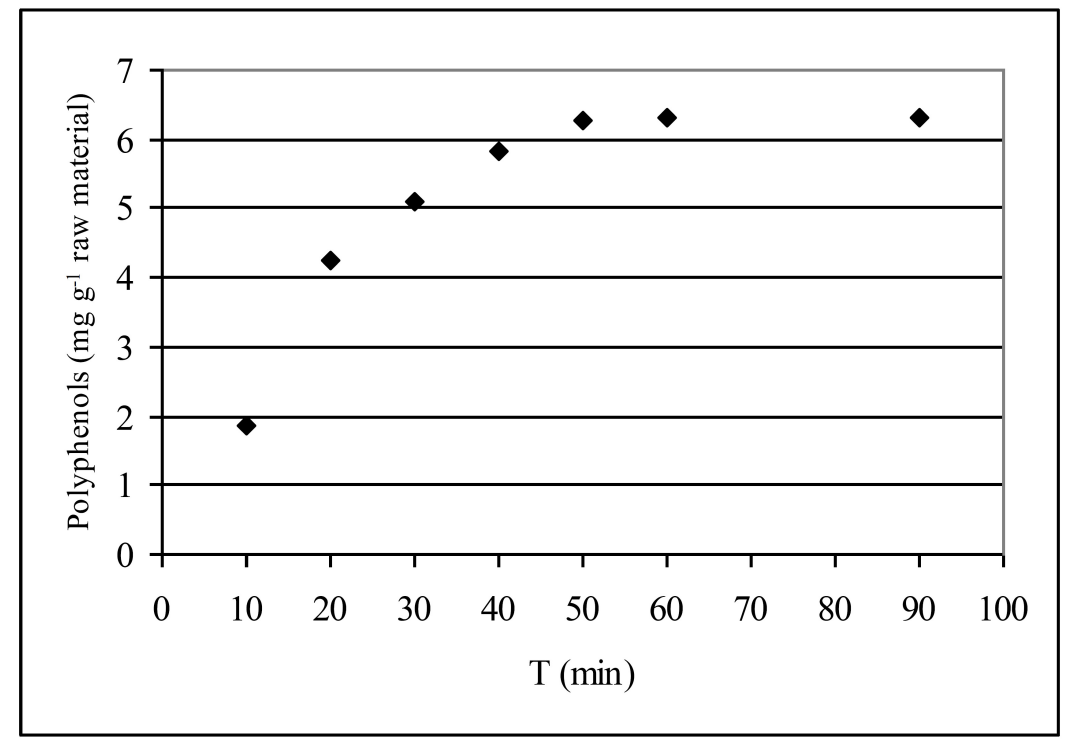

Fig. (1). Kinetics of polyphenols' extraction from vine stems.

Based on our previous experience [18,19], extraction at high temperature, high enough solvent-to-solid ratio, and contact time of about 1 hour creates the necessary conditions for reaching a quasi-equilibrium state, i.e. only insignificant quantity of solid matter is further extracted at longer phase contact. So, the solid-solvent mixture was extracted twice by boiling in a flask under reflux for an hour (temperature about $80^{\circ} \mathrm{C}$ for ethanol-water mixture used, at hydromodule $1 / 10$ - $10 \mathrm{~g}$ plant material and $100 \mathrm{~mL}$ solvent). Both extracts were collected together and sampled for analyses (TR, TPC, and dry matter). The crude liquid extract was then distilled to remove the ethanol. This shifted the phase equilibrium in the residue towards low solubility of resveratrol (which is soluble in ethanol). So, in the absence of ethanol, the target component should precipitate. The separation was aided by cooling the liquid extract in refrigerator $\left(4^{\circ} \mathrm{C}\right)$ for 12 hours, which resulted in sediment formation. The precipitated material was removed by filtration, dried, weighed and then analyzed for TR and TPC. The remaining filtrate was an aqueous solution of the water-soluble components dissolved initially in the crude extract. This filtrate was also dried and analyzed for TR and TPC. As resveratrol was our only target, other polyphenolic compounds were quantified as a group (TPC) and not as single components.

The ethanol-water solvent co-extracts a number of substances soluble in either ethanol or water. The purpose of the above procedure is to separate the total initial extract into two fractions an ethanol-soluble fraction and a water-soluble fraction. The precipitate produced after ethanol removal contains predominantly ethanol-soluble substances, i.e. resveratrol should be retained in the precipitate, while the remaining liquid phase contains predominantly water solublecomponents. Consequently, their separation from the total extract helps to obtain a fraction with higher concentration of the target component.

\section{RESULTS AND DISCUSSION}

Generally, the experiments were carried out in triplicate runs in order to ensure higher accuracy and to check reproducibility. The results reported represent mean values of repeated runs. The experimental results for dried matter yields of total extract, solid residue after ethanol removal ("Ethanol" fraction) and filtrate ("Aqueous" fraction) are given in Table 1 (column C1) as mg of solid matter per $\mathrm{g}$ of raw material.

According to Table 1, which shows quasi-equilibrium state extraction results, the yield of total extracted matter at the above-mentioned extraction conditions is $43.7 \mathrm{mg} \mathrm{g}^{-1}$ raw material (column $\mathrm{C} 1$, row R2), or 4.37\%. Polyphenols are $14.4 \%$ of this crude product $(\mathrm{C} 3, \mathrm{R} 2)$, and the amount of trans-resveratrol is $3.5 \%(\mathrm{C} 2, \mathrm{R} 2)$. 
Table 1. Amounts of extracted matter at quasi-equilibrium state.

\begin{tabular}{|l|c|c|c|c|}
\hline \multicolumn{2}{|c|}{} & C1 & C2 & C3 \\
\cline { 3 - 5 } & \multicolumn{2}{|c|}{ Extracted solid matter $\mathbf{~ m g ~ g ~}^{-1} \mathbf{~ r m}$} & Trans-resveratrol mg g & Polyphenols mg g \\
\hline R1 & Raw material (rm) & - & 1.5 & 6.3 \\
\hline R2 & Dry total extract & 43.7 & 35.0 & 143.7 \\
\hline R3 & "Ethanol" fraction & 4.6 & 284.6 & 295.1 \\
\hline R4 & "Aqueous" fraction & 39.0 & $\sim 0$ & 103.0 \\
\hline
\end{tabular}

After filtration and drying, the precipitate ("Ethanol" fraction) contains $28.5 \%$ trans-resveratrol (C2, R3), which in practice is the full trans-resveratrol content of the total extract since the filtrate ("Aqueous" fraction) is essentially free of resveratrol $(\mathrm{C} 2, \mathrm{R} 4)$. As a result of this proposed separation scheme, the concentration of trans-resveratrol in the "Ethanol" fraction is 8 times higher than in the total extract (R3/R2 of column C2) or 190 times higher compared to its concentration in the raw material (R3/R1 of column $\mathrm{C} 2)$.

Since resveratrol is a phenolic compound, preferably soluble in ethanol, the "Ethanol" fraction contains mostly trans-resveratrol (row R3, C2/C3=0.964) and a small amount of other ethanol-soluble polyphenols (row R3, (C3$\mathrm{C} 2) / \mathrm{C} 3=0.035)$. The dry "Aqueous" fraction contains about $10 \%$ of water-soluble polyphenols $(\mathrm{C} 3$, R4). The part of resveratrol in all extracted polyphenols is about $24 \%$ (row $\mathrm{R} 2, \mathrm{C} 2 / \mathrm{C} 3$ ).

The distribution of TR in the course of the proposed extraction and fractionation method is illustrated in (Fig. 2).

A

B

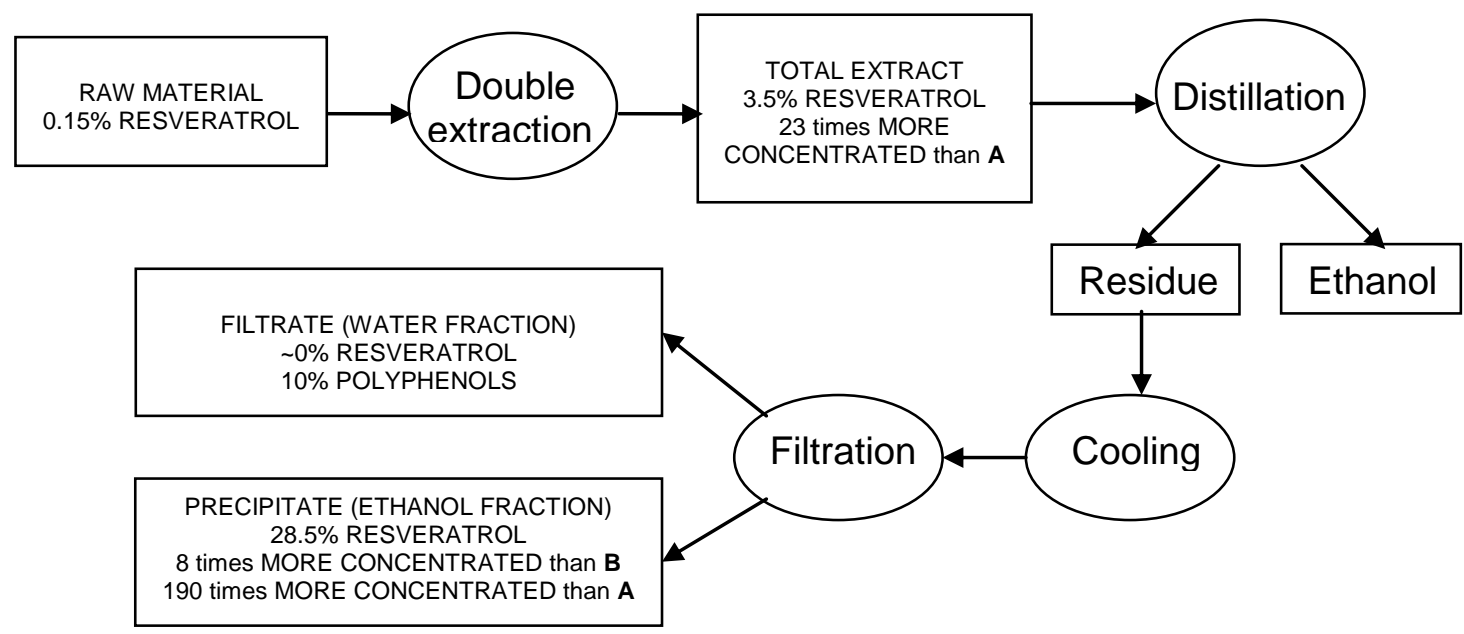

Fig. (2). Process scheme

According to [21], the content of trans-resveratrol in vine stems varies significantly with cultivar and period of pruning. Autumn-harvested stems contain more resveratrol, from 1 to $4.7 \mathrm{mg} \mathrm{g}^{-1}$ stems depending on cultivar. Our results show $1.53 \mathrm{mg} \mathrm{g}^{-1}$, which falls in the above range and quantifies the content of TR in the dry stems of the studied cultivar Cabernet Sauvignon from a local region from a particular year.

\section{CONCLUSION}

An efficient process is developed for recovery of resveratrol from vine stems. Based on shifting of phase equilibrium, this method allows for obtaining significantly more concentrated extracts of resveratrol compared to conventional solid-liquid extraction. To achieve this, the initial extract obtained via classical extraction is further separated into two fractions, containing either water or ethanol soluble compounds, respectively. Using this approach, resveratrol is separated from water-soluble substances and the resulting fraction is about 8 times more concentrated in resveratrol than the initial extract. Additionally, a fraction containing water-soluble polyphenols is obtained, which could be useful for application in water-based pharmaceutical and cosmetic preparations. 
Generally, the proposed method is appropriate for efficient recovery of resveratrol from a widely available renewable natural raw material (grapevine stems) usually treated and discarded as waste otherwise.

\section{CONFLICT OF INTEREST}

The authors confirm that this article content has no conflict of interest.

\section{ACKNOWLEDGEMENTS}

Declared none.

\section{REFERENCES}

[1] M. Takaoka, "Resveratrol, a new phenolic compound from Veratrum grandiflorum", J. Chem. Soc. Japan, vol. 60, pp. 1090-1100, 1939.

[2] P. Langcake, and R.J. Price, "Production of resveratrol by Vitus vinifera as response to infection or injury", Physiol. Plant Pathol., vol. 9, pp. $77-86,1976$.

[http://dx.doi.org/10.1016/0048-4059(76)90077-1]

[3] Q.H. Pan, L. Wang, and J.M. Li, "Amounts and subcellular localization of stilbene synthase in response of grape berries to UV irradiation", Plant Sci., vol. 176, pp. 360-366, 2009. [http://dx.doi.org/10.1016/j.plantsci.2008.12.004]

[4] L.M. Chung, M.R. Park, J.C. Chun, and S.J. Yun, "Resveratrol accumulation and resveratrol synthase gene expression in response to abiotic stresses and hormones in peanut plants", Plant Sci., vol. 164, pp. 103-109, 2003. [http://dx.doi.org/10.1016/S0168-9452(02)00341-2]

[5] J.B. Jiménez, J.M. Orea, A.G. Urena, P. Escribano, P. López de la Osa, and A. Guadarrama, "Short anoxic treatments to enhance transresveratrol content in grapes and wine", Eur. Food Res. Technol. A, vol. 224, pp. 373-378, 2007. [http://dx.doi.org/10.1007/s00217-006-0329-6]

[6] A. Amri, J.C. Chaumeil, S. Sfar, and C. Charrueau, "Administration of resveratrol: What formulation solutions to bioavailability limitations?", J. Control. Release, vol. 158, no. 2, pp. 182-193, 2012. [http://dx.doi.org/10.1016/j.jconrel.2011.09.083] [PMID: 21978644]

[7] J. Constant, "Alcohol, ischemic heart disease, and the French paradox", Clin. Cardiol., vol. 20, no. 5, pp. 420-424, 1997. [http://dx.doi.org/10.1002/clc.4960200504] [PMID: 9134271]

[8] J.M. Wu, Z.R. Wang, T.C. Hsieh, J.L. Bruder, J.G. Zou, and Y.Z. Huang, "Mechanism of cardioprotection by resveratrol, a phenolic antioxidant present in red wine (Review)", Int. J. Mol. Med., vol. 8, no. 1, pp. 3-17, 2001. [PMID: 11408943]

[9] S. Bastianetto, W.H. Zheng, and R. Quirion, "Neuroprotective abilities of resveratrol and other red wine constituents against nitric oxiderelated toxicity in cultured hippocampal neurons", Br. J. Pharmacol., vol. 131, no. 4, pp. 711-720, 2000. [http://dx.doi.org/10.1038/sj.bjp.0703626] [PMID: 11030720]

[10] P. Signorelli, and R. Ghidoni, "Resveratrol as an anticancer nutrient: molecular basis, open questions and promises", J. Nutr. Biochem., vol. 16, no. 8, pp. 449-466, 2005. [http://dx.doi.org/10.1016/j.jnutbio.2005.01.017] [PMID: 16043028]

[11] J. Ferrières, "The French paradox: lessons for other countries", Heart, vol. 90, no. 1, pp. 107-111, 2004. [http://dx.doi.org/10.1136/heart.90.1.107] [PMID: 14676260]

[12] J.A. Baur, K.J. Pearson, N.L. Price, H.A. Jamieson, C. Lerin, A. Kalra, V.V. Prabhu, J.S. Allard, G. Lopez-Lluch, K. Lewis, P.J. Pistell, S. Poosala, K.G. Becker, O. Boss, D. Gwinn, M. Wang, S. Ramaswamy, K.W. Fishbein, R.G. Spencer, E.G. Lakatta, D. Le Couteur, R.J. Shaw, P. Navas, P. Puigserver, D.K. Ingram, R. de Cabo, and D.A. Sinclair, "Resveratrol improves health and survival of mice on a high-calorie diet", Nature, vol. 444, no. 7117, pp. 337-342, 2006. [http://dx.doi.org/10.1038/nature05354] [PMID: 17086191]

[13] D.R. Valenzano, E. Terzibasi, T. Genade, A. Cattaneo, L. Domenici, and A. Cellerino, "Resveratrol prolongs lifespan and retards the onset of age-related markers in a short-lived vertebrate", Curr. Biol., vol. 16, no. 3, pp. 296-300, 2006. [http://dx.doi.org/10.1016/j.cub.2005.12.038] [PMID: 16461283]

[14] W. Wang, K. Tang, H.R. Yang, P.F. Wen, P. Zhang, H.L. Wang, and W.D. Huang, "Distribution of resveratrol and stilbene synthase in young grape plants (Vitis vinifera L. cv. Cabernet Sauvignon) and the effect of UV-C on its accumulation", Plant Physiol. Biochem., vol. 48, no. 2-3, pp. 142-152, 2010.

[http://dx.doi.org/10.1016/j.plaphy.2009.12.002] [PMID: 20060310]

[15] X. Sun, B. Peng, and W. Yan, "Measurement and correlation of solubility of trans-resveratrol in 11 solvents", J. Chem. Thermodyn., vol. 40, pp. 735-738, 2008. [http://dx.doi.org/10.1016/j.jct.2007.10.006]

[16] S. Rayne, E. Karacabey, and G. Mazza, "Grape cane waste as a source of trans-resveratrol and trans-viniferin: High-value phytochemicals with medicinal and anti-phytopatogenic applications", Ind. Crops Prod., vol. 27, pp. 335-340, 2008. [http://dx.doi.org/10.1016/j.indcrop.2007.11.009] 
[17] E. Karacabey, and G. Mazza, "Optimization of solid-liquid extraction of resveratrol and other phenolic compounds from milled grape canes (Vitis vinifera)", J. Agric. Food Chem., vol. 56, no. 15, pp. 6318-6325, 2008. [http://dx.doi.org/10.1021/jf800687b] [PMID: 18636680]

[18] G. Angelov, S.S. Boyadzhieva, and S.S. Georgieva, "Rosehip extraction: Process optimization and antioxidant capacity of extracts", Cent. Eur. J. Chem., vol. 12, pp. 502-508, 2014. [http://dx.doi.org/10.2478/s11532-013-0395-0]

[19] G. Angelov, S. Georgieva, S. Boyadzhieva, and L. Boyadzhiev, "Optimizing the extraction of globe artichoke wastes", C. R. Acad. Bulg. Sci.. in press.

[20] E. Karacabey, and G. Mazza, "Optimization of antioxidant activity of grape cane extracts using response surface methodology", Food Chem., vol. 119, pp. 343-348, 2010.

[http://dx.doi.org/10.1016/j.foodchem.2009.06.029]

[21] Aaviksaar, M. Haga, T. Pussa, M. Roasto, and G. Tsoupras, "Purification of resveratrol from vine stems", Proc. Estonian Acad. Sci., vol. 52, pp. 155-164, 2003.

[22] J.L. Rudolf, A.V. Resurreccion, F.K. Saalia, and R.D. Phillips, "Development of a reverse-phase high-performance liquid chromatography method for analyzing trans-resveratrol in peanut kernels", Food Chem., vol. 89, pp. 623-638, 2005. [http://dx.doi.org/10.1016/j.foodchem.2004.05.033]

[23] V.L. Singleton, and J.A. Rossi, "Colorimetry of total phenolics with phosphomolybdic-phosphotungstic acid reagents", Am. J. Enol. Vitic., vol. 16, pp. 144-158, 1965.

Received: September 17, 2015

Revised: December 17, 2015

Accepted: December 23, 2015

(C) Angelov et al. Licensee Bentham Open.

This is an open access article licensed under the terms of the Creative Commons Attribution-Non-Commercial 4.0 International Public License (CC BY-NC 4.0) (https://creativecommons.org/licenses/by-nc/4.0/legalcode), which permits unrestricted, non-commercial use, distribution and reproduction in any medium, provided the work is properly cited. 